Chapman University

Chapman University Digital Commons

Psychology Faculty Articles and Research

Psychology

$10-2013$

\title{
Is There a Viability-Vulnerability Tradeoff? Sex Differences in Fetal Programming
}

Curt A. Sandman

University of California - Irvine

Laura M. Glynn

Chapman University, lglynn@chapman.edu

Elyssia Poggi Davis

University of California - Irvine

Follow this and additional works at: http://digitalcommons.chapman.edu/psychology_articles

Part of the Maternal and Child Health Commons, and the Obstetrics and Gynecology Commons

\section{Recommended Citation}

Sandman CA, Glynn LM \& Davis EP (2013). Is there a viability-vulnerability tradeoff? Sex differences in fetal programming. Journal of Psychosomatic Research, 75, 327-335.

DOI:10.1016/j.jpsychores.2013.07.009 


\section{Is There a Viability-Vulnerability Tradeoff? Sex Differences in Fetal Programming}

\section{Comments}

NOTICE: this is the author's version of a work that was accepted for publication in Journal of Psychosomatic Research. Changes resulting from the publishing process, such as peer review, editing, corrections, structural formatting, and other quality control mechanisms may not be reflected in this document. Changes may have been made to this work since it was submitted for publication. A definitive version was subsequently published in Journal of Psychosomatic Research, volume 75, 2013. DOI:10.1016/j.jpsychores.2013.07.009

The Creative Commons license below applies only to this version of the article.

\section{Creative Commons License}

\section{(c) 1 (1) 90}

This work is licensed under a Creative Commons Attribution-Noncommercial-No Derivative Works 4.0 License.

\section{Copyright}

Elsevier 


\title{
IS THERE A VIABILITY-VULNERABILITY TRADEOFF? SEX DIFFERENCES IN FETAL PROGRAMMING
}

\author{
CURT A SANDMAN, PhD ${ }^{1}$, LAURA M GLYNN, PhD ${ }^{1,2}$, and ELYSIA POGGI DAVIS, PhD ${ }^{1,3}$ \\ ${ }^{1}$ Women and Children's Health and Well-being Project, Department of Psychiatry \& Human \\ Behavior, University of California, Irvine \\ ${ }^{2}$ Crean School of Health and Life Sciences, Chapman University \\ ${ }^{3}$ Neurodevelopmental Research Program, Department of Psychology, Denver University
}

\section{Abstract}

OBJECTIVE-In this paper we evaluate the evidence for sex differences in fetal programming within the context of the proposed viability-vulnerability tradeoff.

\begin{abstract}
METHODS-We briefly review the literature on the factors contributing to primary and secondary sex ratios. Sex differences in fetal programming are assessed by summarizing previously published sex difference findings from our group (6 studies) and also new analyses of previously published findings in which sex differences were not reported (6 studies).
\end{abstract}

RESULTS-The review and reanalysis of studies from our group are consistent with the overwhelming evidence of increasing risk for viability among males exposed to environmental adversity early in life. New evidence reported here support the argument that females, despite their adaptive agility, also are influenced by exposure to early adversity. Two primary conclusions are (i) female fetal exposure to psychobiological stress selectively influences fear/anxiety, and (ii) the effects of female fetal exposure to stress persist into preadolescence. These persisting effects are reflected in increased levels of anxiety, impaired executive function and neurological markers associated with these behaviors.

CONCLUSIONS-A tacit assumption is that females, with their adaptive flexibility early in gestation, escape the consequences of early life exposure to adversity. We argue that the consequences of male exposure to early adversity threatens their viability, effectively culling the weak and the frail and creating a surviving cohort of the fittest. Females adjust to early adversity with a variety of strategies, but their escape from the risk of early mortality and morbidity has a price of increased vulnerability expressed later in development.

\section{Keywords}

Child development; Fetal behavior; Fetal programming; HPA axis; prenatal stress; Sex differences

(C) 2013 Elsevier Inc. All rights reserved.

CORRESPONDING AUTHOR: CURT SANDMAN, Early Human and Lifespan Development Program, One University Drive, ORANGE, CA 92866, 714-940-1922 (PHONE), 714-940-1939 (FAX) casandma@uci.edu.

Conflict of Interest

The authors declare that they do not have any actual or potential conflict of interest including any financial, personal or other relationships with other people or organizations within three years of beginning the submitted work that could inappropriately influence, or be perceived to influence, their work

Publisher's Disclaimer: This is a PDF file of an unedited manuscript that has been accepted for publication. As a service to our customers we are providing this early version of the manuscript. The manuscript will undergo copyediting, typesetting, and review of the resulting proof before it is published in its final citable form. Please note that during the production process errors may be discovered which could affect the content, and all legal disclaimers that apply to the journal pertain. 


\section{INTRODUCTION}

Environmental pressures on population sex ratios, even prior to conception, dictate that a male or female conceptus will achieve reproductive success. These pressures are reflected in unique patterns of developmental "programming" with consequences that confer risk for morbidity and mortality early in life and vulnerability to disease later in life. It is unknown if there is a "tradeoff" between viability early in life and vulnerability later and if there is, whether it is related to sex differences in patterns of fetal programming. The purpose of this paper is to evaluate the evidence in support of a sex-dependent viability-vulnerability tradeoff established in very early experience.

\section{Sex ratio theory}

An Evolutionary Stable Strategy (ESS) is a concept derived from Game Theory applied to understand population sex ratios [1]. Among the assumptions of ESS are two that are of particular importance; first, adoption of the strategy by all members of the population ensures optimal outcomes and two, invading mutant strategies (for instance by a minority of the population) will not survive. If the mutant strategy becomes more effective over time, more members of the population will adopt it, supplanting the original strategy. The ideal ESS to maintain an optimal balance of different characteristics in the population is a 1:1 ratio of males to females. This is supported by the fact that there is no sex ratio bias in $\mathrm{X}$ to Y sperm [2]. Historical records and current studies [3, 4], however consistently confirm that more males than females are conceived (primary sex ratio) and born (secondary sex ratio). This suggests that under certain conditions, natural selection favors a deviation from the 50/50 ESS sex ratio at conception and birth [5]. Proposed explanations for a male biased ratio are varied and include mechanisms related to population pressures [6], heritable traits [7], genetic programming [8], parental hormone levels [9] and fetal responses (programming) to adversity [9]. But most relevant for the aim of this paper is clear evidence that an objective and crucial birth outcome, secondary sex ratio, is associated with, and perhaps programmed by, preconceptional and maternal/fetal exposures to environmental events.

Fisher [10] argued that sex ratios were determined by parental expenditures or investments (e.g., nurturance) in their offspring and also that this investment should be equal for both sexes. Fisher, however was aware, even in the 1930's (and perhaps Darwin before him [9]), of the sexual disparity in favor of male births. Most explanations for the sex ratio disparity included the contribution of parental investment (PI) in the fetus and infant. Under hostile environmental conditions differential mortality and "programming" of morbidity and developmental impairments are predicted to occur early in pregnancy so that a new reproductive cycle can be initiated and that PI can be directed to another pregnancy [5]. Studies consistently show that more males than females are born preterm [3], that males have poorer neonatal and infant health outcomes [11], have higher risk for motor and cognitive outcomes, are less likely to survive in intensive care, are more likely to have a placental inflammation, decidual lymphoplasmacytic cell infiltration, velamentous umbilical cord insertion $[12,13]$ and show delayed lung maturation compared to females equivalent to one week of gestational age despite their greater size [14]. Under adverse or hostile conditions, males are less likely to survive and more likely to suffer from profound developmental impairments reducing the number of reproductively viable males in the population.

The influential Trivers-Willard (TW) [15] sex ratio hypothesis assumes that the probability of reproductive success of male offspring is more variable and resource-sensitive than female offspring. PI in sons of "good quality" yields greater reproductive success (RS) than 
sons of "poor quality" because their greater size and strength allows them to out-compete their male rivals and dominate available reproductive opportunities $[15,16]$. The TW theory further assumes that PI has less influence on the RS of female offspring because reproductive cycles are much slower in women than men and because almost all females do reproduce some offspring.

Consistent with the majority of findings, the TW model predicts that any environmental stress will always affect males more severely than females in very early life [5] and that these effects have both short and long-term consequences. In a recent report [17], strong evidence was presented for the immediate influence of environmental resources on sex ratios and specifically for a reduction in male births. A three-year famine (1958-1961) in China resulted in as many as 45,000,000 deaths. During this period, there was a significant reduction in male births that did not return to normal proportions (higher ratio of male births) until two years after the famine ended. Conversely, in a developed nation such as the United States, historically birth ratios have favored males, roughly 51.5 to 48.5 percent resulting in 5.8 million "excess" males since 1940 [4]. The TW theory argues that successful evolution and survival in the gene pool are achieved when males are conceived during favorable environmental conditions but that females are the best investment when the resources are poor.

Sexually dimorphic patterns in response to hostile conditions or more specifically stress, may be programmed very early in gestation. The female placenta appears to be more responsive to changes in stress signals such as maternal glucocorticoid concentration than the male placenta resulting in different patterns of growth [18]. Male fetuses invest resources in growth, largely independent of maternal conditions, and this strategy may be a contributor to their larger size at birth. A consequence of the investment in growth is a relative poverty of resources to respond to subsequent exposures to stress and adversity. Because the male fetus has not conserved its resources and does not adapt to maternal signals it has limited ability to adjust to adversity and is at greater risk for subsequent morbidity and mortality. In contrast, the female fetus does not invest as heavily in growth but conserves resources and adjusts to maternal conditions in multiple ways (gene and protein changes), a strategy that is relied on heavily in the context of a hostile or stressful environment. Because of this developmental/evolutionary strategy the female fetus that has conserved its energy needs has increased probability of survival when and if exposed to stress that reduces nutrients and resources later in gestation.

The evidence supports the argument that prenatal exposure to adversity exerts unequal influences on male and female development beginning even before conception. For example, sex differences have been observed in mammalian animal models during meisois. Meisois (not to be confused with miosis) is a special process that creates gametes, the sperm and egg cells, by the combination of two haploid sex cells. The cells divide, without DNA replication resulting in halving of the chromosomal complement. This process is responsible for genetic diversity because of the sharing of genetic information between homologous chromosomes. It is estimated that as many of $25 \%$ of human fetuses have the "wrong" number of chromosomes. When faced with adversity (e.g. engineered mutations) male meiosis is interrupted resulting in infertility [8]. However in females, a similar adversity does not interrupt meiosis. The consequences are that only 3-4\% of sperm are chromosomally abnormal but $20 \%$ of oocytes are anomalous [8]. The early mortality of the male sperm during adverse circumstances reduces male contributions to aneuploidy. The robust and persistent meiosis of oocytes is the major contributor to deviant chromosomal patterns. 
The strong consensus is that consequences of exposure to adversity are exhibited in males very early in the life cycle, even as early as conception and meiosis. The tacit consensus is that females do not exhibit developmental consequences, and that they are largely and relatively immune from, exposure to early adversity. However it is possible that exposure to early adversity influences both male and female conceptuses but that the developmental strategies for response are radically different. There is no question that males exposed to early adversity suffer a much higher risk than females of fetal and infant morbidity and mortality. Because they have been eliminated (high mortality) or weakened (morbidity) the surviving males constitute a relatively homogenous, less variable cohort. In contrast, females adjust to early adversity with a variety of less extreme individually determined strategies and have escaped the severe consequences of high risk for mortality and morbidity. This results in a far greater and more variable behavioral and biological repertoire among females increasing the probability that there will be associations between their developmental trajectories and early life exposures. In this paper we evaluate the evidence for sex differences in fetal programming within the context of the proposed viability-vulnerability tradeoff by review and reanalysis of data from our existing studies (see Table 1).

\section{GENERAL METHODS}

We have developed a longitudinal, prospective protocol to advance the understanding of prenatal influences on birth outcome and infant and child development. Our protocol includes maternal psychosocial and biological stress measures collected at five gestational intervals beginning between 14 and 16 weeks. Maternal/fetal dyads are assessed at 15, 20, 25,31 and 36 weeks of gestation. At $\sim 25, \sim 31$ and $\sim 36$ gestational weeks, fetal neurodevelopment is evaluated with measures of startle and habituation. Infant assessments begin 24 hours post delivery with the collection of HPA hormones and behavioral responses to the painful stress of the heel-stick procedure and measures of neonatal neuromuscular maturity. Infant cognitive, neuromotor development, stress and emotional regulation are evaluated at 3, 6, 12 and 24 months of age. Maternal psychosocial and demographic information is collected in parallel with infant assessments. Child neurodevelopment is assessed between 6-9 years of age with cognitive tests, measures of adjustment and brain imaging. Multiple assessments during gestation and during follow-up are essential because there are critical periods both for the effects of programming on the nervous system and for the expression of subsequent behaviors. All of our studies include normative samples of healthy mothers and infants/children. Further, in all cases the consequences of prenatal stress are present after considering stable demgraphic characteristics (maternal age, race/ ethnicity and SES) and carefully characterized postnatal influences such as maternal stress, anxiety and depression. Table 1 summarizes previously published and new findings from these studies that reveal sex-specific effects of early life experience. In all of the studies described below associations are independent of birth outcome (e.g. birth weight and gestational age at birth) and appropriate covariates such as socioeconomic status and postnatal maternal psychological state (e.g., postpartum depression).

\section{RESULTS}

\section{Maternal cortisol selectively shapes female fetal neurological development (previously reported in Glynn \& Sandman, 2012 [19])}

Recently we reported the relation between prenatal maternal cortisol levels and fetal movement (FM) response to vibroacoustic stimulation (VAS) in 190 mother-fetus pairs. Fetal responses to VAS are exhibited at 25 gestational weeks although at this age the response is developing and not observed in all fetuses. As the central nervous system (CNS) develops, this response matures and becomes more robust. By 31 gestational weeks most 
fetuses display a large increase in movement in response to the VAS followed by sustained elevations in movement and by 37 weeks fetuses display a more regulated response characterized by a rapid return to baseline after the initial increase. Maternal cortisol influences the developing fetal CNS and is associated with the developmental trajectory of the response to VAS. Early elevations in cortisol predicted a failure to respond to the VAS at 25 weeks ( $p<0.01$ ). This suggests that early elevations disrupt fetal CNS development leading to a less mature response to VAS. In contrast, exposure to elevations in cortisol late in gestation was associated with a larger and more mature response among fetuses when assessed near term $(\mathrm{p}<0.01)$. These data are consistent with evidence that exposure to maternal cortisol at the end of gestation promotes fetal maturation in preparation for birth.

Sex specific responses to stress signals are observed during the fetal period. The associations between cortisol and VAS emerged earlier and were strongest among female fetuses. Specifically, the association between elevated maternal cortisol early in gestation and diminished FM response to the VAS at 25 weeks in the entire cohort is predominantly present among the females. Further, the association between elevated maternal cortisol late in gestation and a well-developed FM response at 31 weeks gestation also is more apparent among the females. These findings may be consistent with the reports of the sexual dimorphism of placental glucocorticoid receptor and function [18]. The female, but not the male placenta adjusts its glucocorticoid metabolic activity in response to cortisol exposures. Because adrenal cortisol easily passes the blood brain barrier and binds with receptors in many cortical and subcortical areas the metabolic differences between sexes results in unique patterns of brain activation and perhaps can account for the responses to the VAS we observed here [20-24]. Our findings provide new support for the role that prenatal glucocorticoids can play in shaping human fetal CNS development and for the sexually dimorphic sensitivity to prenatal maternal signals in the human fetus.

\section{Sex specific consequences of maternal prenatal stress hormone exposure for neonatal neuromuscular maturation (previously reported in Ellman et al., 2009[25])}

Concentrations of placental corticotrophin-releasing hormone (CRH) and maternal cortisol were determined from plasma collected from 158 women at 15, 19, 25, and 31 weeks' gestation. Newborn physical and neuromuscular maturation was evaluated with the New Ballard Maturation index. Published results indicated that elevated maternal cortisol at 15, 19 , and 25 weeks and increased concentration of placental CRH at 31 weeks were significantly associated with decreased physical and neuromuscular maturation after adjusting for length of gestation.

Supplementary analyses to examine programming differences for male and female neonates indicated that the significant findings for maternal cortisol at $15(\mathrm{p}<0.01)$ and $19(\mathrm{p}<0.01)$ weeks and placental CRH at $31(\mathrm{p}<0.01)$ weeks were significant only among males. Male fetuses exposed to elevated levels of cortisol early in pregnancy and CRH late in pregnancy exhibited delayed physical and neuromuscular maturation in very early infancy. Conversely, a trend suggested that elevated maternal cortisol at 31 weeks was associated with increased or accelerated maturation (total Ballard score) in females.

This was the first study to report that the timing of fetal exposure to stress hormones had sex-specific effects on maturation at birth. The finding that exposure to stress hormones was associated with delays or immaturity in males is consistent with the evidence that male exposure to adversity results in risk for morbidity. The trend for a possible acceleration in females is a novel finding that also may be consistent with the belief that the female fetus adjusts and adapts to environmental challenge. It is important to acknowledge that the results of sex-specific programming effects reported in this study were observed in neonates 
because it is a developmental period immediately after birth and before the effects of postnatal influences, including parental investments can be consequential.

\section{Males are more susceptible to the effects of early maternal cortisol on mental development at one year of age (new analysis of data presented in Davis \& Sandman, 2010 [26])}

Maternal cortisol was prospectively evaluated in 125 mother-infant pairs and infant mental and motor development was assessed at 12 months of age using the Bayley Scales of Infant Development (BSID;[27]). The original publication showed that elevated maternal cortisol early in gestation was associated with impaired mental development at 1 year of age among infants born full term. New analyses of these data revealed that the negative association between prenatal maternal cortisol and 12 month mental development was significant only among male infants $(\mathrm{p}<0.05)$. These data suggest that males are more susceptible to the effects of early maternal cortisol on developmental delays during infancy. This finding that prenatal stress hormone exposure has a greater effect on general cognitive ability among males is consistent with evidence that early adversity is associated with male immaturity at birth.

\section{Prescience appears earlier in females (new analysis of data presented in Sandman, Davis and Glynn, 2012[28])}

We previously reported enhanced psychomotor (PDI) and mental development (MDI) during the first year of life among infants whose mothers experienced congruent levels of depressive symptoms during and after pregnancy. Symptoms of maternal depression were assessed at regular intervals throughout the pregnancies and postpartum in a sample of 221 healthy women. For analysis, infants were separated into four groups. Two groups included infants whose mothers reported congruent prenatal and postnatal depression; either high levels or low levels both pre- and post-partum. The other two groups reported incongruent symptoms pre- and post-partum. At 3 months of age, infants in the two congruent groups performed significantly better than infants in the two discrepant groups on measures of PDI. By six months of age, infants in the congruent groups achieved superior performance on both PDI and MDI measures compared with infants in the two discrepant groups. By 12 months of age, infants in the congruent groups continued to have higher scores only on the MDI scores. There was no main effect to indicate that exposure to maternal depression preor postpartum alone influenced mental or psychomotor development at any age. We concluded that the congruence between prenatal and postnatal environments prepared the fetus for postnatal life and conferred an adaptive advantage for critical survival functions during early development.

Reanalysis of these published data examining sex differences are illustrated in Figure 1. The effect of a congruent maternal environment at 6 months of age was due only to the superior performance of females for both the PDI and MDI. By 12 months of age, sex differences were not apparent and the effects of congruence were significant for both sexes on the MDI. The findings may indicate that female infants adapt more quickly than male infants to conditions that are essential for survival. The pattern of adaptation is identical for males and females, but it occurs early in development for females with possible consequences for outcomes later in life.

\section{Placental CRH and maternal depression increases risk for fearful infant temperament among girls (new analyses of data presented in Davis et al., 2005[29])}

We have previously reported that fetal exposure to elevated maternal depression and placental CRH at 25 gestational weeks in 248 women are independent risk factors for fearful or reactive temperament during infancy. New analyses illustrated that these effects are observed only among females. Specifically, elevated placental CRH at 25 gestational weeks 
was significantly associated with more fearful temperament [partial $r(95)=0.23, \mathrm{p}<0.05]$ and higher levels of distress behavior [partial $r(95)=0.38, p<0.01$ ] among female infants, but not male infants (p's $>0.2$ ). Interestingly a similar pattern was observed for prenatal maternal depression. Elevated levels of depression at 25 gestational weeks were associated with more fearful temperament during infancy for girls [partial $\mathrm{r}(93)=0.21$, $\mathrm{p}<0.05$ ], but not for boys $(\mathrm{p}=0.09)$. Hierarchical linear regression analyses were performed to determine the cumulative risk associated with gestational exposure to maternal depression and placental $\mathrm{CRH}$. These new analyses indicated elevated placental CRH $\left(\Delta \mathrm{R}^{2}=0.05, \mathrm{~B}=.22, \mathrm{t}=2.2 ; \mathrm{p}\right.$ $<0.05)$ and elevated prenatal maternal depression $\left(\Delta R^{2}=0.04, \mathrm{~B}=.21, \mathrm{t}=2.1 ; \mathrm{p}<0.05\right)$ at 25 gestational weeks independently predicted fearful temperament during infancy only for girls. After statistically considering relevant covariates including postpartum depression, placental CRH and maternal depression accounted for an additional 9\% of the variance in infant fearful temperament among girls but not boys.

\section{Late gestational exposure to elevated maternal cortisol is associated with fearful infant temperament and child anxiety in girls (New analyses of data presented in Davis et al, 2007 and Davis \& Sandman 2012[30, 31])}

We have reported that prenatal exposure to maternal cortisol is associated significantly with fearful temperament in infancy and risk for anxiety problems in childhood. New analyses of these published findings statistically adjusted for confounding factors including gestational age at birth, postpartum and current measures of maternal psychological distress illustrated that in both cases the association is strongest among females. Infant fearful temperament in healthy, full term infants was assessed at 2 months of age using the fear subscale of the Infant Behavior Questionnaire [32]. Elevated maternal cortisol at 30 gestational weeks was significantly associated with infant fearful temperament at 2 months of age among girls [partial $\mathrm{r}(128)=0.18, \mathrm{p}<0.05$ ], but not boys $(\mathrm{p}=0.22)$. Moreover, the sex specific association between prenatal maternal cortisol and fear/anxiety persists into the preadolescent period. Elevated maternal cortisol at 30 gestational weeks significantly predicts anxiety (Child Behavior Checklist; CBCL [33]) in preadolescent girls [partial $\mathrm{r}(80)=0.23, \mathrm{p}<0.05$ ] but no significant association was observed among boys $[\mathrm{p}=0.8]$. These findings indicate that the female fetus is more susceptible than the male fetus to the consequences of exposure to maternal cortisol for fear and anxiety.

\section{Cortisol in human milk predicts temperament in female infants, but not males (Previously reported in Grey et al., 2012 [34])}

In a recent published report, we examined the possibility that human breast milk may represent an important pathway through which the mother continues to shape the development of her offspring. Specifically, this study examined the relation between cortisol levels in human breast milk and temperament of the breastfed infant. Fifty-two mother and infant pairs participated when the infants were three-months old. Cortisol levels from breast milk were assessed and each mother completed the Infant Behavior Questionnaire [32]. Analyses revealed that elevated concentrations of cortisol in breast milk were associated with infant negative temperament. Importantly, this association was not explained by indicators of parenting such as postpartum depression. Further, the association between breast milk cortisol and negative temperament was present among girls $(\mathrm{p}<0.05)$, but not among boys ( $\mathrm{p}=0.92$ ). The findings suggest that mothers have the ability to shape offspring phenotype through the transmission of biologically active components in breast milk, and that these influences appear to be the most potent for female offspring. These findings are consistent with evidence from the prenatal period that early life exposure to elevated maternal cortisol may program a vulnerability to anxiety problems among girls. 
Brain volume is reduced in females exposed to elevated levels of maternal pregnancy anxiety (Previously reported in Sandman et al., 2011[35])

Recently, our group published the first study to show that fetal exposure to pregnancy specific anxiety (PSA) was related to changes in brain morphology at six to nine years of age independent of birth phenotype [36]. Specifically, PSA early in gestation was associated with gray matter volume reductions in the prefrontal cortex, the premotor cortex, the medial temporal lobe, the lateral temporal cortex, the postcentral gyrus as well as the cerebellum extending to the middle occipital gyrus and the fusiform gyrus. These brain regions are associated with a variety of functions including executive cognitive functions such as behavioral/emotional regulation, inhibitory processes, reasoning, planning, attention, working memory, and some aspects of language and memory.

Subsequent analysis of these data indicated that the significant $(\mathrm{p}<0.01)$ reduction in brain volume in 6-9 year old children exposed to elevated PSA early in gestation primarily were observed in girls [35]. There virtually was no effect of fetal exposure to maternal pregnancy specific anxiety in male gray matter volume. These data suggest that there is a persisting influence of prenatal exposure to maternal adversity in females and that the effects are apparent in areas of brain critical for executive function, including emotional regulation and inhibition and for language and memory.

\section{Maternal pregnancy anxiety influences executive function in girls (Previously reported in Buss et al., 2011[37])}

The effects of maternal PSA, generalized anxiety and depression on executive (cognitive) function were assessed in 6-9 year old children. Serial data were collected in 89 women at $15,19,25,31$ and 37 weeks gestation. Maternal prenatal pregnancy-specific anxiety was a stronger predictor of executive function in the offspring than maternal prenatal state anxiety or depression. Accompanying analysis indicated that the association between high levels of mean maternal pregnancy-specific anxiety at mid-gestation but not later and poor performance on tests of executive function was observed only in girls.

Because executive functions, including emotional regulation and inhibitory control, are coordinated by activity within the prefrontal cortex, these findings are consistent with the association between reduced gray matter volume and pregnancy anxiety described above [38]. Poor performance is associated with reduced brain volume and these two consequences were observed only in girls exposed to elevated maternal pregnancy anxiety at midgestation. This is further evidence that persisting influences of prenatal exposures are more common in females than males.

\section{Fetal exposure to maternal cortisol is associated with increased amygdala volume and affective problems in preadolescent girls (Previously reported in Buss et al., 2012[39])}

The association of maternal cortisol in early, mid and late gestation with amygdala and hippocampal volume was determined in 65 normal, healthy mother-child dyads. Elevated maternal cortisol at 15 weeks gestation but not later was associated with a significantly larger right amygdala volume in girls but not in boys. This strong effect was significant after adjusting for factors associated with pregnancy, birth outcome and current child and maternal characteristics. Moreover, we reported that the association between fetal exposure to high levels of maternal cortisol early in gestation and subsequent affective problems in children was mediated by an enlarged right amygdala. The findings from this study support the argument that fetal exposures to maternal signals of stress and adversity have persisting effects on the female nervous system and subsequent behavior. Further, they are consistent with our behavioral data linking gestational cortisol exposure to risk for fearful and anxious behavior only among females. 
Sex Specific Associations between Gestational Age at Birth and Gray Matter Volume at 6 to 10 years of Age (New analyses of data presented in Davis et al., 2011[40])

We have reported that children born at later gestational ages have regionally specific increases in grey matter volume during preadolescence (All subjects: Figure 2). This significant association was observed even when only full term children were included. New analyses presented here were performed to evaluate the association between gestational age at birth and gray matter volume in the identified regions of interest separately for male and female children (See Table 2 and Figure 3). For females, longer gestation was associated with increased gray matter volume bilaterally in the superior and middle temporal gyrus (BA 21,22 ) extending ventrally to the occipitotemporal gyrus/fusiform gyrus (BA 20) and medially to the insula. Associations between longer gestation and increased gray matter volume also were present in the left parietal lobe (BA 40 and 7) and the left cerebellum. For males, the association between greater gestational age at birth and gray matter volume was confined to bilateral increases in the superior and middle temporal gyrus (BA 21). Notably the relation between gestational length and subsequent development was evident among this low risk cohort of children with a stable neonatal course, who did not experience common perinatal risk factors for neurological impairment such as mechanical ventilation, intraventricular hemorrhage, or periventricular leukomalacia.

Rapid changes in the development and organization of the fetal brain occur throughout the entire course of gestation [41, 42]. Accordingly, we found that even modest differences in gestational length shape the construction of the healthy fetal nervous system and alter the trajectory of neurodevelopment, with consequences that persist for at least 6 to 10 years. In this low risk sample, we found that female fetuses are more susceptible than male fetuses to the persisting influences of gestational length. Although length of gestation was associated with regionally specific alterations in brain morphology at 6 to 10 years of age for both male and female children, the effect was strongest among females. The differential consequences of length of gestation for girls and boys is consistent with both the sex specific trajectories of fetal development $[43,44]$ and the fact that the emergence of neurodevelopmental disorders originating during the prenatal period varies by sex [45, 46]. The greater susceptibility of low risk female children to the consequences of gestational length observed in the current study differs from the greater vulnerability of males to extreme preterm birth $[47,48]$, but is consistent with a recent report showing that in a low risk sample, birth weight was only associated with adult hippocampal volume in females [49].

\section{CONCLUSIONS}

The purpose of this paper is to examine the evidence that there is a sex-dependent tradeoff between early life viability and later life vulnerability as a consequence of fetal exposure to adversity. To accomplish this, we briefly reviewed an extensive literature on the factors contributing to primary and secondary sex ratios. The rationale for examining the sex ratio literature was to establish a basis for expecting sex differences in response to early adversity. We reasoned that if biological sex itself is influenced by early environmental exposures, then the influence of environmental exposures on males and females would be programmed differently.

There is overwhelming evidence that more males are conceived and born during periods of prosperity. There is an equally large literature indicating elevated risk for morbidity and mortality (viability) in males born exposed to environmental adversity [5]. The review of studies from our group is consistent with this evidence. We report that fetal and infant males exhibited developmental delays in important markers of neonatal maturity that are related to morbidity in comparison to females when exposed to elevated levels of stress hormones and 
psychosocial stress. Our studies support the extensive literature that males suffer maturational delays when exposed to prenatal adversity.

A tacit assumption examined here is that females, with their adaptive flexibility early ingestation, escape the consequences of early life exposure to adversity. Published findings and new analyses of previously published reports presented here support the argument that females, despite their adaptive agility, are influenced by exposure to early adversity. There were two primary and novel findings that support a viability-vulnerability tradeoff and suggest that the adaptive strategy implemented by female fetuses may render them susceptible to more subtle, but persisting consequences. Our data consistently show a vulnerability that is associated with increased risk for anxiety and affective problems. First, female fetal exposure to psychobiological stress selectively influences fearful temperament and anxiety risk. Increased fearful or reactive behavior was observed in the female infants after fetal exposure to elevated levels of maternal stress and stress hormones. Further, postnatal exposure to maternal hormones may further tune the development of female infant temperament, but not males [34]. Compared to the developmental delays, morbidity, mortality and generally depressed viability in males, the relatively subtle effects in females may have been overlooked. However, infants who are easily aroused by varied stimulation are more likely to become behaviorally inhibited as young children [50,51], exhibit social anxiety during adolescence [52] and show greater amygdalar activation to novelty as adults [53]. Our data suggest that female fetuses are more susceptible than males to the consequences of prenatal maternal depression, prenatal and postnatal maternal cortisol and placental CRH on infant behaviors that may indicate prodromal risk for affective problems.

The second finding was that the effects of female fetal exposure to stress persisted into preadolescence, as suggested above. These effects were reflected in increased levels of anxiety, impaired executive function and neurological markers associated with these behaviors. For instance, girls, but not boys exposed to elevated levels of maternal cortisol early in pregnancy had significantly enlarged amygdala and increased levels of anxiety in childhood. Highly consistent with our infant findings, exposure to early adversity appears to program risk for affective problems among girls, but not boys. Six-to-nine year old girls but not boys exposed to high levels of pregnancy specific anxiety early in gestation additionally performed poorly on tests of executive function and had decreased gray matter volume in areas of the brain critical for emotional regulation, inhibitory control and memory. One reason that vulnerabilities in females have not been often observed is that there are very few longitudinal, prospective studies of early life experience in humans. A second reason is that the effects in females, although potentially profound have attracted less attention because their consequences are subtle compared to the compromised early viability in males.

A recent study presents data and a hypothesis that support our argument that there is a sexdependent viability-vulnerability trade-off during early development [54]. In a cohort in whom there was a marked decrease in males births several months after the 9/11 attack, higher than expected mental development scores were measured in males but not females. Because the frail have been eliminated (high mortality) or weakened (morbidity) the surviving "culled male cohort" constitute a relatively homogenous, less variable cohort of the strongest and the fittest. In contrast, because females adjust to early adversity with a variety of strategies they have escaped the severe consequences of high risk for mortality and morbidity. However, similar to the resistance of oocytes to mutations during meiosis, this adaptation has a price. Just as subsequent chromosomal errors in the population can be traced to the contribution of female germ cell, the effects of fetal exposure to early adversity in females are manifested in a highly variable behavioral and biological repertoire. This variability increases the probability that there will be associations between their 
developmental trajectories and early life exposures-- the price for enhanced viability is reflected in greater vulnerability among females.

Although it is possible that sexually dimorphic responses to early life experience (e.g. more fearful temperaments only among girls exposed prenatally to higher levels of maternal cortisol) are due to genetic influences, there are a number of reasons to increase confidence that shared genetics do not solely account for these effects. First, findings from animal models in which random assignment to conditions is possible, are consistent with the fetal programming framework (e.g. [55]). Second, in our work and the work of others, significant associations between early life exposures and outcomes persist after adjusting for maternal genetic or familial factors. Third, we have shown previously that among formula-fed infants, maternal postnatal cortisol does not predict temperament, whereas among breastfed infants the same positive association between maternal cortisol and infant temperament is observed [34]. This is significant because maternal circulating cortisol levels are the source of milk cortisol and the two are fairly tightly correlated. These findings argue against a genetic explanation at least for the associations between postnatal cortisol exposures and infant temperament because the genetic influences underlying the relations would be unique to breastfeeding mothers, a highly implausible selectivity. Finally, the findings that early life stress is related to several child outcomes in related and unrelated (in-vitro fertilization) mother-offspring pairs strongly support the argument that influences other than genetic influences child outcomes [56].

\section{Acknowledgments}

Supported by awards NS-41298, HD-51852 and HD28413 to CAS, HD-50662 and HD065823to EPD and HD-40967 to LMG. The assistance of Cheryl Crippen, Megan Faulkner, Christina Canino Brown, Natalie Hernandez, Kendra Leak and Kevin Head is gratefully acknowledged.

\section{References}

1. Smith, JM. On Evolution. Edinburgh University Press; 1972. Game theory and the evolution of fighting.

2. Graffelman J, Fugger EF, Keyvanfar K, Schulman JD. Human live birth and sperm-sex ratios compared. Hum Reprod. 1999; 14:2917-20. [PubMed: 10548648]

3. Cooperstock M, Campbell J. Excess males in preterm birth: interactions with gestational age, race, and multiple birth. Obstet Gynecol. 1996; 88:189-93. [PubMed: 8692499]

4. Mathews TJ, Hamilton BE. Trend analysis of the sex ratio at birth in the United States. Natl Vital Stat Rep. 2005; 53:1-17.

5. Wells JC. Natural selection and sex differences in morbidity and mortality in early life. J Theor Biol. 2000; 202:65-76. [PubMed: 10623500]

6. Argasinski K. The dynamics of sex ratio evolution dynamics of global population parameters. J Theor Biol. 2012; 309:134-46. [PubMed: 22683379]

7. Kanazawa S. Beautiful british parents have more daughters. Reprod Sci. 2011; 18:353-8. [PubMed: 21321241]

8. Hunt PA, Hassold TJ. Sex matters in meiosis. Science. 2002; 296:2181-3. [PubMed: 12077403]

9. James WH. Hypotheses on the stability and variation of human sex ratios at birth. J Theor Biol. 2012; 310:183-6. [PubMed: 22776504]

10. Fisher, RA. The Genetical Theory of Natural Selection Clarendon Press. Oxford: 1930.

11. Peacock JL, Marston L, Marlow N, Calvert SA, Greenough A. Neonatal and infant outcome in boys and girls born very prematurely. Pediatr Res. 2012; 71:305-10. [PubMed: 22258087]

12. Aiken CE, Ozanne SE. Sex differences in developmental programming models. Reproduction. 2013; 145:R1-13. [PubMed: 23081892] 
13. Walker MG, Fitzgerald B, Keating S, Ray JG, Windrim R, Kingdom JC. Sex-specific basis of severe placental dysfunction leading to extreme preterm delivery. Placenta. 2012; 33:568-71. [PubMed: 22513321]

14. Torday JS, Nielsen HC, de Fencl MM, Avery ME. Sex differences in fetal lung maturation. Am Rev Respir Dis. 1981; 123:205-8. [PubMed: 6894519]

15. Trivers RL, Willard DE. Natural selection of parental ability to vary the sex ratio of offspring. Science. 1973; 179:90-2. [PubMed: 4682135]

16. Kanazawa S. Violent men have more sons: further evidence for the generalized Trivers-Willard hypothesis (gTWH). J Theor Biol. 2006; 239:450-9. [PubMed: 16246373]

17. Song S. Does famine influence sex ratio at birth? Evidence from the 1959-1961 Great Leap Forward Famine in China. Proc Biol Sci. 2012; 279:2883-90. [PubMed: 22456881]

18. Clifton VL. Review: Sex and the human placenta: mediating differential strategies of fetal growth and survival. Placenta. 2010; 31 (Suppl):S33-9. [PubMed: 20004469]

19. Glynn LM, Sandman CA. Sex moderates associations between prenatal glucocorticoid exposure and human fetal neurological development. Dev Sci. 2012; 15:601-10. [PubMed: 22925508]

20. Herman JP, Cullinan WE. Neurocircuitry of stress: central control of the hypothalamo-pituitaryadrenocortical axis. Trends Neurosci. 1997; 20:78-84. [PubMed: 9023876]

21. Joels M, Baram TZ. The neuro-symphony of stress. Nat Rev Neurosci. 2009; 10:459-66. [PubMed: 19339973]

22. Kapoor A, Dunn E, Kostaki A, Andrews MH, Matthews SG. Fetal programming of hypothalamopituitary-adrenal function: prenatal stress and glucocorticoids. J Physiol. 2006; 572:31-44. [PubMed: 16469780]

23. Mueller BR, Bale TL. Sex-specific programming of offspring emotionality after stress early in pregnancy. J Neurosci. 2008; 28:9055-65. [PubMed: 18768700]

24. Rodrigues SM, LeDoux JE, Sapolsky RM. The influence of stress hormones on fear circuitry. Annu Rev Neurosci. 2009; 32:289-313. [PubMed: 19400714]

25. Ellman LM, Dunkel-Schetter C, Hobel CJ, Chicz-DeMet A, Glynn LM, Sandman CA. Timing of fetal exposure to stress hormones: Effects on newborn physical and neuromuscular maturation. Developmental Psychobiology. 2008; 50:232-41. [PubMed: 18335490]

26. Davis EP, Sandman CA. The timing of prenatal exposure to maternal cortisol and psychosocial stress is associated with human infant cognitive development. Child Development. 2010; 81:13148. [PubMed: 20331658]

27. Bayley, N. Balyley Scales of Infant Development. 2. The Psychological Corporation; 1993.

28. Sandman CA, Davis EP, Glynn LM. Prescient human fetuses thrive. Psychol Sci. 2012; 23:93100. [PubMed: 22173740]

29. Davis EP, Glynn LM, Dunkel Schetter C, Hobel C, Chicz-Demet A, Sandman CA. Corticotropinreleasing hormone during pregnancy is associated with infant temperament. Dev Neurosci. 2005; 27:299-305. [PubMed: 16137987]

30. Davis EP, Sandman CA. Prenatal psychobiological predictors of anxiety risk in preadolescent children. Psychoneuroendocrinology. 2012; 37:1224-33. [PubMed: 22265195]

31. Davis EP, Glynn LM, Schetter CD, Hobel C, Chicz-Demet A, Sandman CA. Prenatal exposure to maternal depression and cortisol influences infant temperament. J Am Acad Child Adolesc Psychiatry. 2007; 46:737-46. [PubMed: 17513986]

32. Gartstein MA, Rothbart MK. Studying infant temperament via the revised infant behavior questionnaire. Infant Behavior \& Development. 2003; 26:64-86.

33. Achenbach, TM.; Rescorla, LA. Manual for the ASEBA School-Age Forms and Profiles: An Integtated System of Multi-Informant Assessment. Burlington, VT: University of Vermont, Reaserch Center for Children, Youth, \& Families; 2001.

34. Grey KR, Davis EP, Sandman CA, Glynn LM. Human milk cortisol is associated with infant temperament. Psychoneuroendocrinology. 2012

35. Sandman CA, Davis EP. Neurobehavioral risk is associated with gestational exposure to stress hormones. Expert Rev Endocrinol Metab. 2012; 7:445-59. [PubMed: 23144647] 
36. Buss C, Davis EP, Muftuler LT, Head K, Sandman CA. High pregnancy anxiety during midgestation is associated with decreased gray matter density in 6-9-year-old children. Psychoneuroendocrinology. 2010; 35:141-53. [PubMed: 19674845]

37. Buss C, Davis EP, Hobel CJ, Sandman CA. Maternal pregnancy-specific anxiety is associated with child executive function at 6-9 years age. Stress. 2011; 14:665-76. [PubMed: 21995526]

38. Sandman CA, Davis EP, Buss C, Glynn LM. Exposure to Prenatal Psychobiological Stress Exerts Programming Influences on the Mother and Her Fetus. Neuroendocrinology. 2012; 95:8-21.

39. Buss C, Davis EP, Shahbaba B, Pruessner JC, Head K, Sandman CA. Maternal cortisol over the course of pregnancy and subsequent child amygdala and hippocampus volumes and affective problems. Proc Natl Acad Sci U S A. 2012; 109:E1312-9. [PubMed: 22529357]

40. Davis EP, Buss C, Muftuler LT, Head K, Hasso A, Wing DA, et al. Children's Brain Development Benefits from Longer Gestation. Front Psychol. 2011; 2:1. [PubMed: 21713130]

41. Bourgeois JP. Synaptogenesis, heterochrony and epigenesis in the mammalian neocortex. Acta Paediatr Suppl. 1997; 422:27-33. [PubMed: 9298788]

42. Volpe, JJ. Neurology of the newborn. 5. Philedelphia: Elsevier; 2008.

43. DiPietro JA, Costigan KA, Shupe AK, Pressman EK, Johnson TR. Fetal neurobehavioral development: associations with socioeconomic class and fetal sex. Dev Psychobiol. 1998; 33:79_ 91. [PubMed: 9664173]

44. Buss C, Davis EP, Class QA, Gierczak M, Pattillo C, Glynn LM, et al. Maturation of the human fetal startle response: Evidence for sex-specific maturation of the human fetus. Early Hum Dev. 2009

45. Goel N, Bale TL. Examining the intersection of sex and stress in modelling neuropsychiatric disorders. J Neuroendocrinol. 2009; 21:415-20. [PubMed: 19187468]

46. Gabory A, Attig L, Junien C. Sexual dimorphism in environmental epigenetic programming. Mol Cell Endocrinol. 2009; 304:8-18. [PubMed: 19433243]

47. Hintz SR, Kendrick DE, Vohr BR, Kenneth Poole W, Higgins RD. For The Nichd Neonatal Research N. Gender differences in neurodevelopmental outcomes among extremely preterm, extremely-low-birthweight infants. Acta Paediatr. 2006; 95:1239-48. [PubMed: 16982497]

48. Kesler SR, Reiss AL, Vohr B, Watson C, Schneider KC, Katz KH, et al. Brain volume reductions within multiple cognitive systems in male preterm children at age twelve. J Pediatr. 2008; 152:513-20. 20 e1. [PubMed: 18346506]

49. Buss C, Lord C, Wadiwalla M, Hellhammer DH, Lupien SJ, Meaney MJ, et al. Maternal care modeulates the relationship between prenatal risk and hippocampal volume in women but not in men. The Journal of Neuroscience. 2007; 27:2592-5. [PubMed: 17344396]

50. Kagan J, Snidman N, Arcus D. Childhood derivatives of high and low reactivity in infancy. Child Development. 1998; 69:1483-93. [PubMed: 9914634]

51. Pfeifer M, Goldsmith HH, Davidson RJ, Rickman M. Continuity and change in inhibited and uninhibited children. Child Development. 2002; 73:1474-85. [PubMed: 12361313]

52. Schwartz CE, Snidman N, Kagan J. Adolescent social anxiety as an outcome of inhibited temperament in childhood. Journal of the American Academy of Child and Adolescent Psychiatry. 1999; 38:1008-15. [PubMed: 10434493]

53. Schwartz CE, Wright CI, Shin LM, Kagan J, Rauch SL. Inhibited and uninhibited infants "grown up": adult amygdalar response to novelty. Science. 2003; 300:1952-3. [PubMed: 12817151]

54. Bruckner TA, Nobles J. Intrauterine stress and male cohort quality: the case of September 11, 2001. Soc Sci Med. 2013; 76:107-14. [PubMed: 23153542]

55. Weinstock M. Alterations induced by gestational stress in brain morphology and behaviour of the offspring. Progress in Neurobiology. 2001; 65:427-51. [PubMed: 11689280]

56. Rice F, Harold GT, Boivin J, van den Bree M, Hay DF, Thapar A. The links between prenatal stress and offspring development and psychopathology: disentangling environmental and inherited influences. Psychological Medicine. 2010; 40:335-45. [PubMed: 19476689] 
MENTAL DEVELOPMENT

(MDI)
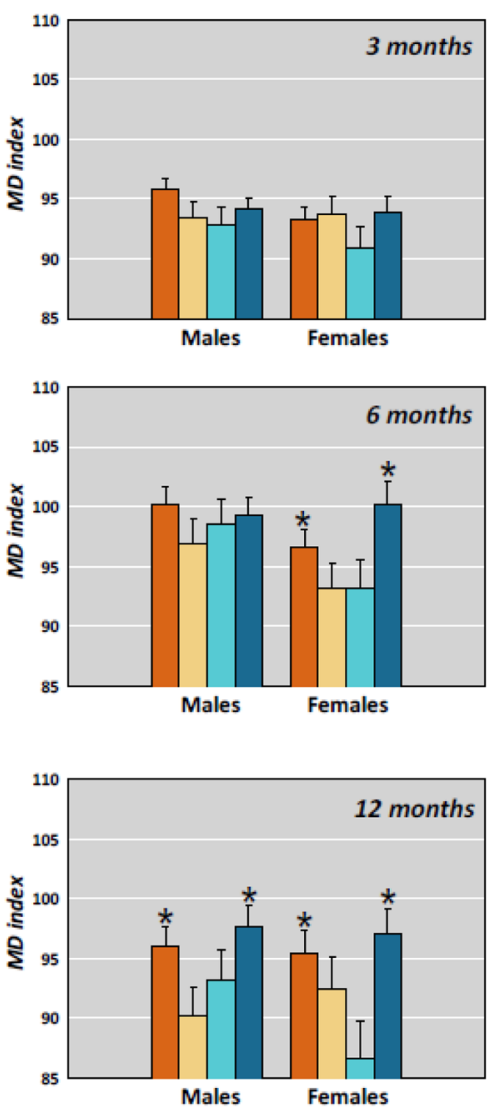

PSYCHOMOTOR DEVELOPMENT

(PDI)
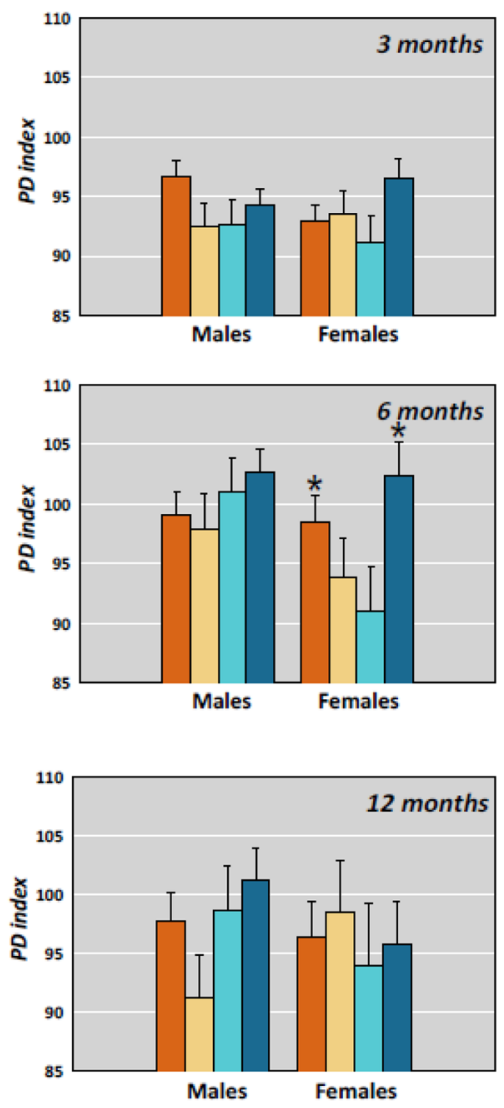

Figure 1.

Mental (MDI) and Psychomotor (PDI) development in male and female infants at 3, 6 and 12 months who were exposed to maternal depression during pregnancy and at 3 months postpartum. Female infants exposed to congruent prenatal and postnatal maternal depression (NoDep/NoDep and Dep/Dep) have superior mental and psychomotor development compared with infants exposed to discordant maternal depression (NoDep/Dep ande Dep/ NoDep) at six months of age. By 12 months of age, both male and female infants exposed to congruent maternal depressive symptoms have superior MDI. * $(\mathrm{p}<0.05$; comparison is between groups, within sex. Error bars are sem. 


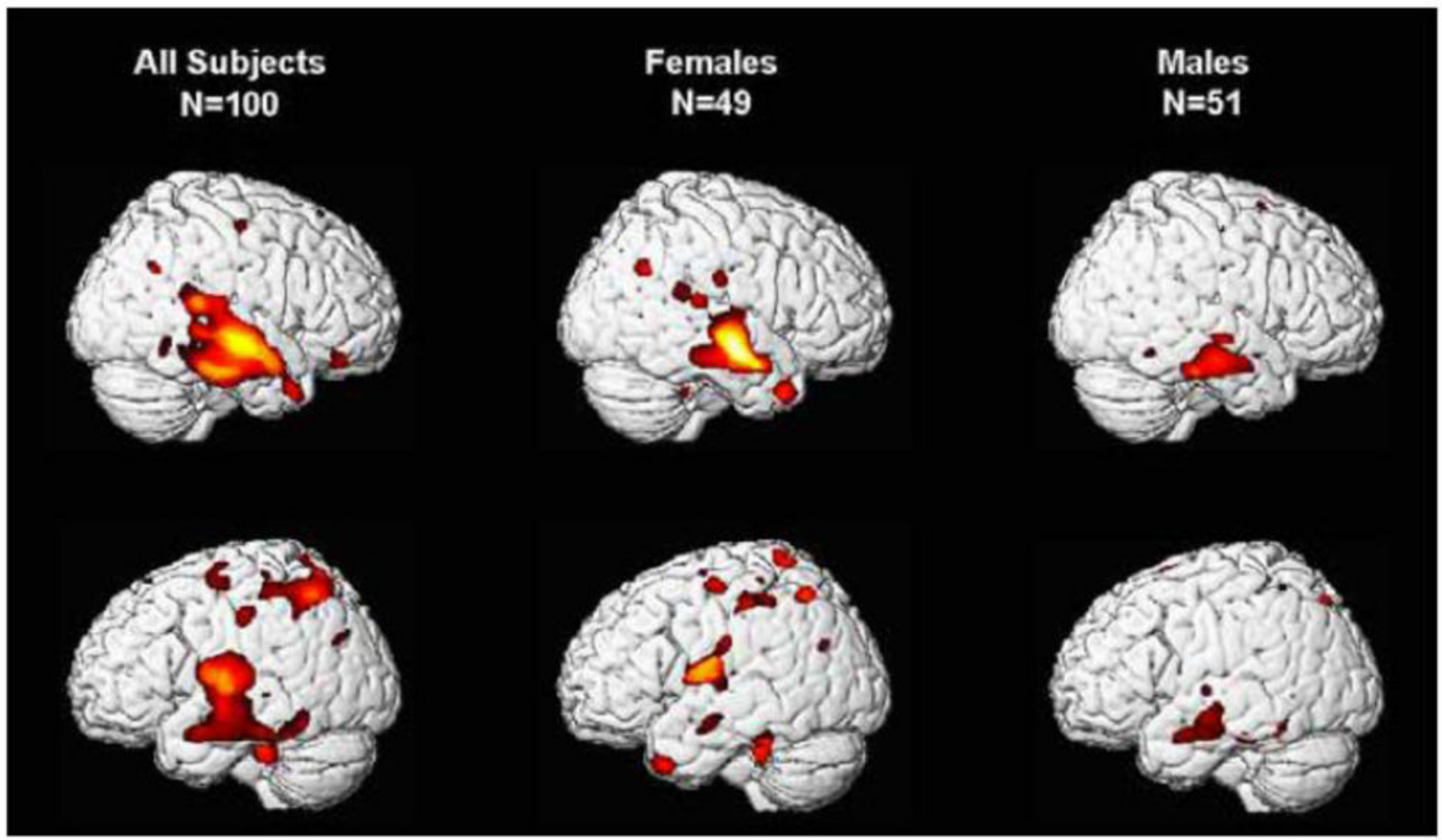

Figure 2.

Longer gestation is associated with significant bilateral increases in grey matter volume (VBM) primarily in the temporal lobe for all preadolescent subjects. The overall effect is due primarily to the effects observed in preadolescent girls. Hot colors denote significantly $(\mathrm{p}<0.05$ to 0.01$)$ greater volume associates with gestational age at birth. 


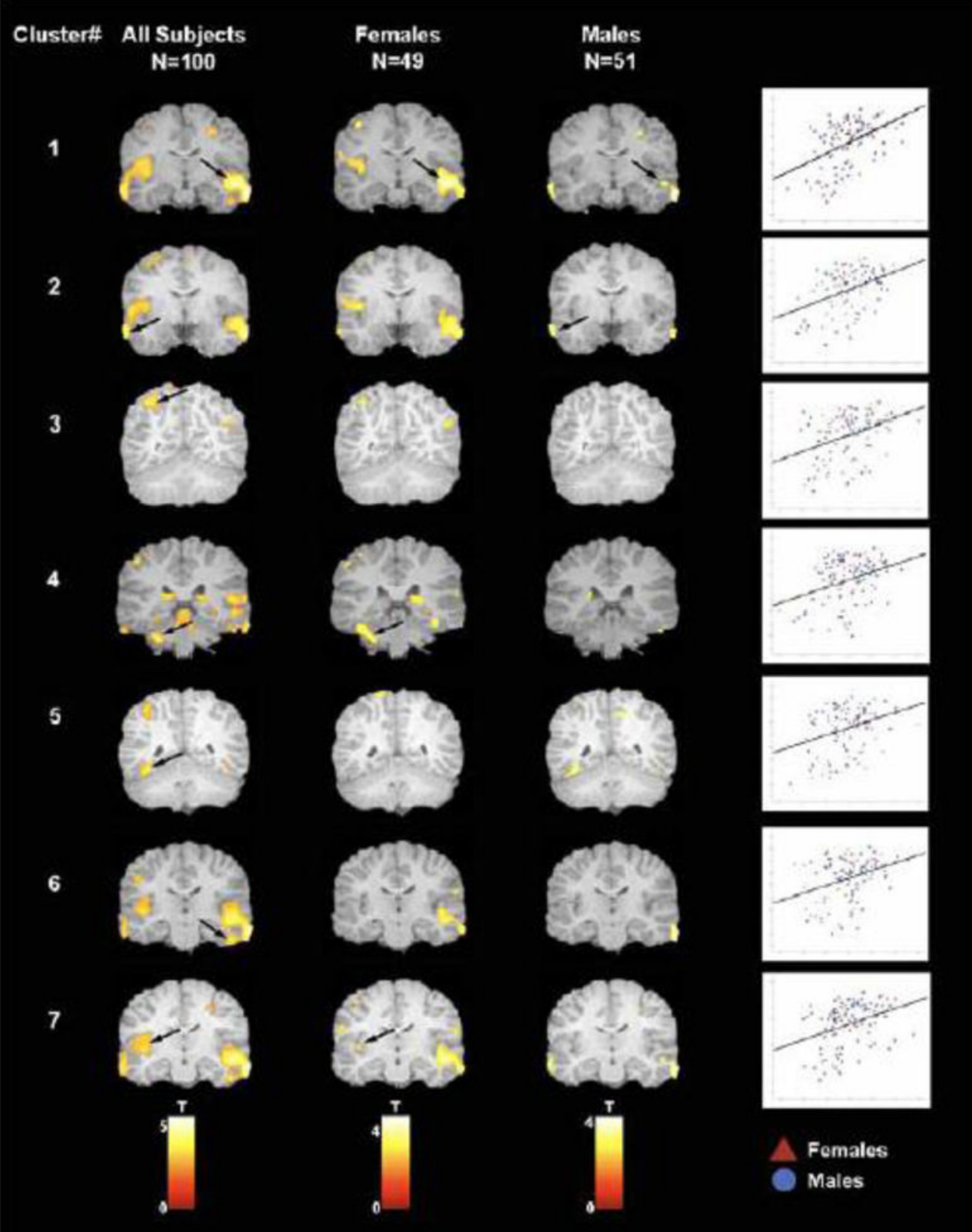

Figure 3.

Areas of increased grey matter volume in association with longer gestational length are displayed for each of the seven regions of interest (See Table 2) for: (i) the complete sample (column 1), (ii) males (column 2) and (iii) females (column 3). Arrows indicate clusters that remained significant at $\mathrm{p}<.05$ after FDR correction. Scatter plots demonstrate the association between gestational age at birth (y axis) and cluster value (x axis) for each of the seven regions of interest. Red triangles are females and blue circles are males. 
Table 1

\begin{tabular}{|c|c|c|c|}
\hline \multicolumn{2}{|l|}{ STUDY } & \multirow{2}{*}{$\begin{array}{l}\text { PARTICIPANTS } \\
190 \text { Mothers ( } 83 \\
\text { female/107 male } \\
\text { fetuses) }\end{array}$} & \multirow{2}{*}{$\begin{array}{l}\text { PRIMARY SEX-SPECIFIC FINDINGS } \\
\text { Relations between maternal cortisol and fetal response to } \\
\text { vibroacoustic stimulation were stronger for females. Among } \\
\text { females, maternal cortisol was predictive of fetal behavior in } \\
\text { response to stimulation at an earlier age than among males. }\end{array}$} \\
\hline Fetus & $\begin{array}{l}\text { Glynn \& Sandman (2012). Sex } \\
\text { moderates associations between } \\
\text { prenatal glucocorticoid exposure and } \\
\text { human fetal neurological development. } \\
\text { Developmental Science, 15, 601-610. }\end{array}$ & & \\
\hline Neonate & $\begin{array}{l}\text { Ellman, Dunkel-Schetter, Hobel, } \\
\text { Chicz-Demet, Glynn \& Sandman } \\
\text { (2008). Timing of fetal exposure to } \\
\text { stress hormones: Effects on newborn } \\
\text { physical and neuromuscular } \\
\text { maturation. Developmental } \\
\text { Psychobiology, } 50,232-241 .\end{array}$ & $\begin{array}{l}158 \text { Mothers }(80 \\
\text { female/ } / 78 \text { male } \\
\text { neonates) }\end{array}$ & $\begin{array}{l}\text { The association between fetal exposure to elevated maternal } \\
\text { cortisol and placental CRH and delayed neuromuscular } \\
\text { development was observed only among male neonates. }\end{array}$ \\
\hline \multirow{5}{*}{ Infant } & Sandman, Glynn, Davis $2013^{1}$ & $\begin{array}{l}165 \text { Mothers ( } 60 \\
\text { female/ } 65 \text { male infants) }\end{array}$ & $\begin{array}{l}\text { The association between exposures to elevated maternal } \\
\text { cortisol early in gestation and impaired cognitive } \\
\text { performance at 1-year of age was stronger among males. }\end{array}$ \\
\hline & Sandman, Glynn, Davis $2013^{2}$ & $\begin{array}{l}221 \text { Mothers (103 } \\
\text { female/118 male } \\
\text { infants) }\end{array}$ & $\begin{array}{l}\text { Congruence between exposure to maternal depression in the } \\
\text { pre and postnatal environments was associated with } \\
\text { advanced maturation of motor and mental abilities in 1-year } \\
\text { - old infants. Effects were observed at an earlier age among } \\
\text { female infants. }\end{array}$ \\
\hline & Sandman, Glynn, Davis $2013^{3}$ & $\begin{array}{l}248 \text { Mothers ( } 116 \\
\text { females/ } 132 \text { males) }\end{array}$ & $\begin{array}{l}\text { Elevated placental CRH at } 25 \text { gestational weeks is } \\
\text { associated with more fearful temperament and higher levels } \\
\text { of distress behavior among female infants, but not male } \\
\text { infants at } 2 \text { months of age. }\end{array}$ \\
\hline & Sandman, Glynn, Davis $2013^{3}$ & $\begin{array}{l}248 \text { Mothers (116 } \\
\text { females/ } 132 \text { males) }\end{array}$ & $\begin{array}{l}\text { Increased maternal depressive symptomatology at } 25 \\
\text { gestational weeks predicted more fearful temperament } \\
\text { during infancy among girls, but not boys. }\end{array}$ \\
\hline & $\begin{array}{l}\text { Grey, Davis, Sandman \& Glynn } \\
\text { (2012). Human milk cortisol is } \\
\text { associated with infant temperament } \\
\text { Psychoneuroendocrinology, 37, 1224- } \\
1233 \text {. }\end{array}$ & $\begin{array}{l}52 \text { Mothers ( } 27 \text { female/ } \\
25 \text { male infants) }\end{array}$ & $\begin{array}{l}\text { The positive association between milk cortisol and fearful } \\
\text { infant temperament at } 3 \text { months of age was observed only } \\
\text { among female infants. }\end{array}$ \\
\hline \multirow{5}{*}{ Child } & $\begin{array}{l}\text { Sandman, Davis, Buss \& Glynn } \\
\text { (2011). Exposure to prenatal } \\
\text { psychobiological stress exerts } \\
\text { programming influences on the mother } \\
\text { and her fetus. Neuroendocrinology. }\end{array}$ & $\begin{array}{l}35 \text { Mothers (17 girls/18 } \\
\text { boys) }\end{array}$ & $\begin{array}{l}\text { Elevated pregnancy specific anxiety early in pregnancy is } \\
\text { associated with reduced gray matter volumes. This effect is } \\
\text { seen primarily in girls. }\end{array}$ \\
\hline & $\begin{array}{l}\text { Buss C., Davis, EP, Hobel, CJ and } \\
\text { Sandman, CA (2011). Maternal } \\
\text { pregnancy anxiety is associated with } \\
\text { child executive function at 6-9 years } \\
\text { age. Stress } 14,665-676 .\end{array}$ & $\begin{array}{l}89 \text { Mothers ( } 39 \text { girls } / 50 \\
\text { boys) }\end{array}$ & $\begin{array}{l}\text { Pregnancy-specific anxiety predicted executive function in } \\
\text { girls, but not boys. }\end{array}$ \\
\hline & Sandman, Glynn, Davis $2013^{4}$ & $\begin{array}{l}178 \text { Mothers ( } 98 \text { girls/ } \\
80 \text { boys) }\end{array}$ & $\begin{array}{l}\text { The relation between prenatal maternal cortisol and child } \\
\text { anxiety was stronger among girls. }\end{array}$ \\
\hline & $\begin{array}{l}\text { Buss, Davis, Shahbaba, Pruessner, } \\
\text { Head \& Sandman (2012). Maternal } \\
\text { cortisol over the course of pregnancy } \\
\text { and subsequent child amygdala and } \\
\text { hippocampus volumes and affective } \\
\text { problems. Proceedings of the National } \\
\text { Academy of Sciences. 109, E1312- } \\
1319 \text {. }\end{array}$ & $\begin{array}{l}65 \text { Mothers ( } 35 \text { girls } / 30 \\
\text { boys) }\end{array}$ & $\begin{array}{l}\text { Reduction in brain volumes in } 6-9 \text { year-old children } \\
\text { exposed to elevated maternal cortisol early in gestation } \\
\text { primarily was observed in girls. }\end{array}$ \\
\hline & Sandman, Glynn, Davis $2013^{5}$ & $\begin{array}{l}100 \text { Mothers ( } 49 \text { girls/ } \\
51 \text { boys) }\end{array}$ & $\begin{array}{l}\text { The association between longer gestation and increased gray } \\
\text { matter density is stronger among girls. }\end{array}$ \\
\hline
\end{tabular}

Data from the following previously published studies were reanalyzed to evaluate sex differences. These new findings are presented in the current manuscript:

${ }^{1}$ Davis \& Sandman (2010). The timing of prenatal exposure to maternal cortisol and psychosocial stress is associated with human infant cognitive development. Child Development, 81, 131-148. 
2

sandman, Davis \& Glynn LM (2012). Prescient human fetuses thrive. Psychological Science 23, 93-100.

3 Davis, E. P., Glynn, L. M., Dunkel Schetter, C., Hobel, C., Chjcz-Demet, A., \& Sandman, C. A. (2005). Maternal plasma corticotropin-releasing hormone levels during pregnancy are associated with infant temperament Developmental Neuroscience 27, $299-305$.

${ }^{4}$ Davis \& Sandman (2012). Exposure to prenatal maternal psychobiological stress increases anxiety in preadolescent children Psychoneuroendocrinology 37, 1224-1233.

5 Davis, Buss, Muftuler, Head, Hasso, Wing, Hobel \& Sandman, (2011). Children's brain development benefits from longer gestation Frontiers in Developmental Psychology 2, 1-7 
